\title{
Review of titania nanotubes synthesized via the hydrothermal treatment: Fabrication, modification, and application
}

\author{
Hsin-Hung Ou, Shang-Lien Lo* \\ Environmental Pollution Prevention and Control Technology, Graduate Institute of Environmental Engineering, \\ National Taiwan University, 71 Chou-Shan Road, Taipei 106, Taiwan, ROC
}

\begin{abstract}
In spite of the controversy about the chemical structure and formation mechanism of titania nanotubes (TNTs), they are still gaining prominence owing to their unique features including large specific surface area, photocatalytic potential, and ion-exchangeable ability. In view of this, a comprehensive list of literatures on characterizations, formation mechanism, and applications of TNTs was compiled and reviewed. From a literature survey, it is apparent that the dependence of TNT attributes on the synthesis conditions and on the post-treatments significantly dominates the feasibility of applications. So far, studies intended for rapid formation kinetics and for modifications of TNTs are not exhaustive. That may be the promising aspects in the following developments of TNTs.
\end{abstract}

(C) 2007 Elsevier B.V. All rights reserved.

Keywords: Titania nanotubes; Hydrothermal treatment; $\mathrm{TiO}_{2}$

\section{Introduction}

Nanosize materials with peculiar properties are not expected in bulk phase and have already led to a breakthrough in various fields of science and technology. Over the past decades, nanosize materials derived from $\mathrm{TiO}_{2}$ have extensively been investigated for vast applications, including solar cells/batteries, electroluminescent hybrid devices, and photocatalysis, owing to their peculiar chemical and physical behaviors. Moreover, the discovery of carbon nanotubes intrigued the intensive researches of one-dimensional nanostructures, such as nanotube, nanorod, nanowire, and nanobelts. $\mathrm{TiO}_{2}$-based nanotubes, therefore, attracted extensive and engrossing interest, despite the crystalline structure still being controversial. $\mathrm{TiO}_{2}$-based nanotubes with high specific surface area, ion-changeable ability, and photocatalytic ability have been considered for extensive applications. Currently developed methods of fabricating $\mathrm{TiO}_{2}$-based nanotubes comprise the assisted-template method [1-3], the sol-gel process [4], electrochemical anodic oxidation [5-10], and hydrothermal treatment [11-23]. The scenario of fabrication approaches for $\mathrm{TiO}_{2}$-based nanotubes is demonstrated in Fig. 1. $\mathrm{TiO}_{2}$-based nanotubes were first reported by Hoyer [1] via the template-assisted method. Thereafter,

\footnotetext{
* Corresponding author. Tel.: +886 23625373; fax: +886223928830.

E-mail address: sllo@ccms.ntu.edu.tw (S.-L. Lo).
}

electrochemical anodic oxidation and hydrothermal treatment succeeded in fabricating TNTs. Each fabrication method can have unique advantages and functional features and comparisons among these three approaches have been compiled in Table 1. Regarding the template-assisted method, anodic aluminum oxide (AAO) nanoporous membrane, which consists of an array of parallel straight nanopores with uniform diameter and length, is usually used as template. The scale of TNTs can be moderately controlled by applied templates. However, the template-assisted method often encounters difficulties of prefabrication and post-removal of the templates and usually results in impurities. Concerning electrochemical anodic oxidation, the self-assembled $\mathrm{TiO}_{2}$ nanotubes $\left(\pi-\mathrm{TiO}_{2}\right)$ with highly ordered arrays was discovered by Grimes' group [6], and the method is based on the anodization of Ti foil to obtain nanoporous titanium oxide film [5]. They also demonstrated the crystallization and structure stability of $\pi-\mathrm{TiO}_{2}$ [7]. The comprehensive reviews associated with the fabrication factors, characterizations, formation mechanism, and the corresponding applications of $\mathrm{TiO}_{2}$-based nanotubes arrays have been also conducted by Grimes' group [24]. These methods, other than the hydrothermal process, are either not suitable for large scale production or not able to yield very low dimensional, well separated, crystallized nanotubes [25]. The demonstrated architecture of $\mathrm{TiO}_{2}$-based nanotubes constructed via the hydrothermal treatment is capable of good crystalline formation and establishment of a pure-phase structure in one step in a tightly closed vessel. 


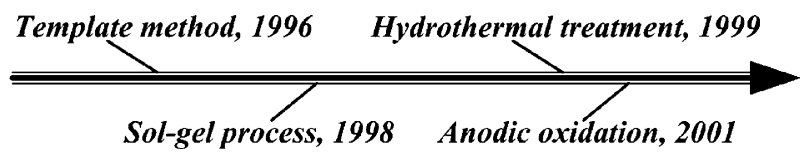

Fig. 1. The scenario of fabrication methods in $\mathrm{TiO}_{2}$-based nanotubes.

Among the aforementioned fabrication approaches, both electrochemical anodic oxidation and hydrothermal treatment received wide investigations, owing to their cost-effective, easy route to obtain nanotubes, and the feasibility/availability of widespread applications. With intention to more detailed discussions, this paper highlights $\mathrm{TiO}_{2}$-based nanotubes synthesized via hydrothermal treatment, for which the corresponding physical and chemical attributes are tailored to the extensive applications. It is, therefore, essential to understand the various factors influencing the characterizations of $\mathrm{TiO}_{2}$-based nanotubes synthesized via hydrothermal treatment. Also, it should be noted that either the modification of hydrothermal treatment or the post-treatment of $\mathrm{TiO}_{2}$-based nanotubes would dominate the corresponding features of TNTs, in other words, the feasibility of the application is subject to the pretreated conditions. Based on extensive literature reviews with regard to $\mathrm{TiO}_{2}$-nased nanotubes, the authors have categorized five broad groups, characterizations and formation mechanism, the effects of fabrication factors and washing process, post-treatments, modifications, and applications, which are further subdivided into their pertinent studies. Fig. 2 shows the research scenario of hydrothermal treatment related to the technical aspects which are further elucidated in the following materials. Readers are referred to the listed references for more detail related to the experimental methodology and conditions.

\section{Characterizations and formation mechanism of TNTs}

$\mathrm{TiO}_{2}$-based nanotubes, with specific surface area of $400 \mathrm{~m}^{2} \mathrm{~g}^{-1}$ and $8 \mathrm{~nm}$ in diameter, via hydrothermal treatment was first reported by Kasuga et al. [4] who assigned the obtained nanotubes for the anatase phase. Their following research also demonstrated the formation mechanism of nanotubes [11]. The

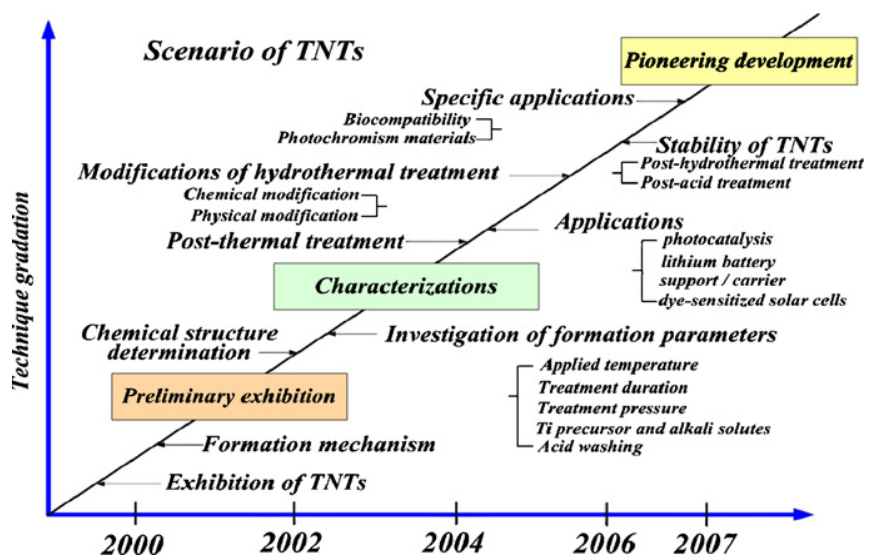

Fig. 2. Research scenario of TNTs synthesized via the hydrothermal treatment.

Table 2

Proposed chemical structures of TNTs and their corresponding lattice parameters

\begin{tabular}{ll}
\hline Chemical structure & Lattice parameters \\
\hline Anatase $\mathrm{TiO}_{2}$ & Tetragonal; $a=3.79 \mathrm{~nm}, b=3.79$, \\
& $c=2.38$ \\
$\mathrm{~N}_{2} \mathrm{Ti}_{3} \mathrm{O}_{7}, \mathrm{Na}_{2} \mathrm{Ti}_{3} \mathrm{O}_{7}, \mathrm{Na}_{x} \mathrm{H}_{2-x} \mathrm{Ti}_{3} \mathrm{O}_{7}$ & $\begin{array}{l}\text { Monoclinic; } a=1.926 \mathrm{~nm}, b=0.378, \\
\end{array}$ \\
$\mathrm{H}_{2} \mathrm{Ti}_{2} \mathrm{O}_{4}(\mathrm{OH})_{2}, \mathrm{Na}_{2} \mathrm{Ti}_{2} \mathrm{O}_{4}(\mathrm{OH})_{2}$ & Orthorhombic; $a=1.808 \mathrm{~nm}$, \\
& $b=0.379, c=0.299$ \\
$\mathrm{H}_{x} \mathrm{Ti}_{2-x / 4} \square_{x / 4} \mathrm{O}_{4}\left(\mathrm{H}_{2} \mathrm{O}\right)$ & Orthorhombic; $a=0.378 \mathrm{~nm}$, \\
$\mathrm{H}_{2} \mathrm{Ti}_{4} \mathrm{O}_{9}\left(\mathrm{H}_{2} \mathrm{O}\right)$ & $b=1.874, c=0.298$ \\
& Monoclinic; $a=1.877 \mathrm{~nm}, b=0.375$, \\
& $c=1.162, \beta=104.6^{\circ}$ \\
\hline
\end{tabular}

present debate over the crystal structure of $\mathrm{TiO}_{2}$-based nanotube is among the following: anatase $\mathrm{TiO}_{2}[11,26-28]$; lepidocrocite $\mathrm{H}_{x} \mathrm{Ti}_{2-x / 4} \square \square_{x / 4} \mathrm{O}_{4} \quad(x \sim 0.7, \quad \square:$ vacancy $)[29,30] ; \quad \mathrm{H}_{2} \mathrm{Ti}_{3} \mathrm{O}_{7} /$ $\mathrm{Na}_{2} \mathrm{Ti}_{3} \mathrm{O}_{7} / \mathrm{Na}_{x} \mathrm{H}_{2-x} \mathrm{Ti}_{3} \mathrm{O}_{7}$ [12-15,19,32,33]; $\mathrm{H}_{2} \mathrm{Ti}_{2} \mathrm{O}_{4}(\mathrm{OH})_{2} /$ $\mathrm{Na}_{2} \mathrm{Ti}_{2} \mathrm{O}_{4}(\mathrm{OH})_{2} / \mathrm{Na}_{x} \mathrm{H}_{2-x} \mathrm{Ti}_{2} \mathrm{O}_{5}\left(\mathrm{H}_{2} \mathrm{O}\right) \quad[16,17,20-23,34,35]$; $\mathrm{H}_{2} \mathrm{Ti}_{4} \mathrm{O}_{9} \quad\left(\mathrm{H}_{2} \mathrm{O}\right)$ [36]. The lattice parameters for each chemical structure are shown in Table 2. From literature surveys, the chemical composition of $\mathrm{Na}_{x} \mathrm{H}_{2-x} \mathrm{Ti}_{3} \mathrm{O}_{7}$ and $\mathrm{Na}_{x} \mathrm{H}_{2-x} \mathrm{Ti}_{2} \mathrm{O}_{4}(\mathrm{OH})$ groups were more acceptable than other structures. As such, the following will emphasize the characterizations and formation mechanisms of these two

Table 1

Comparisons of current methods in TNT fabrication

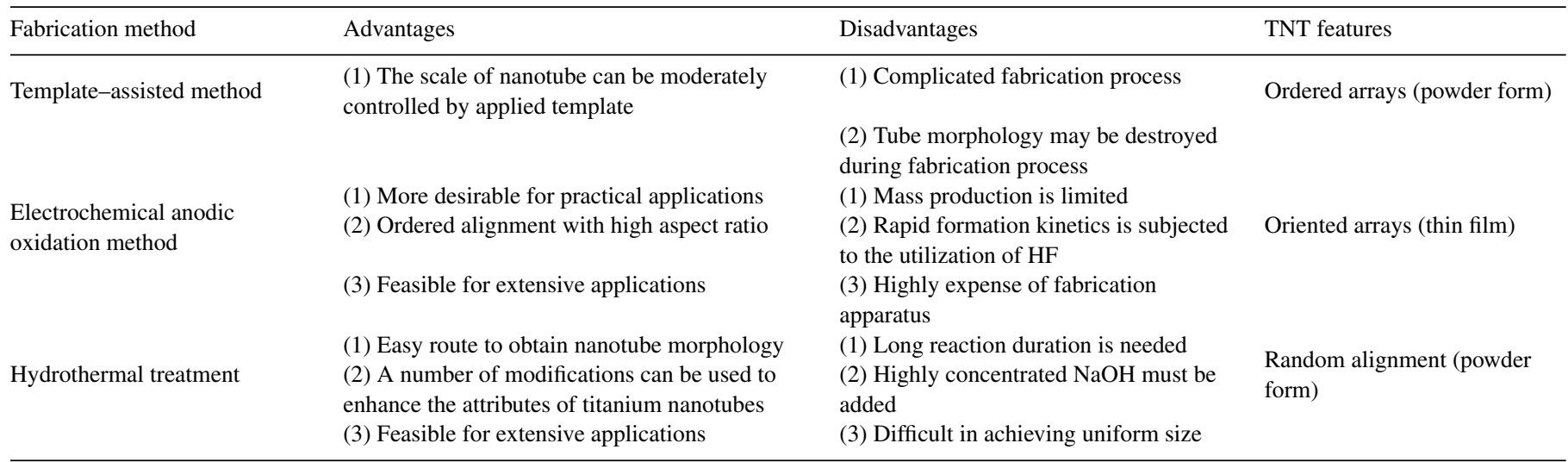


structures in terms of some special and novel techniques, where $\mathrm{TiO}_{2}$-based nanotubes are abbreviated as TNTs and not subject to any structure mentioned above. Even though some attempts have been dedicated to the formation mechanism of TNTs, an explicit explanation is unavailable because the chemical structure of TNTs is still controversial. Moreover, TNTs were proposed to form either before or after acid washing treatment; Kasuga et al. [11] tentatively suggested that the formation of TNTs was achieved after acid washing, while Peng's group [12] reported that TNTs can form during the reaction of $\mathrm{TiO}_{2}$ with $\mathrm{NaOH}$ in hydrothermal treatment.

\subsection{The group of $\mathrm{Na}_{x} \mathrm{H}_{2-x} \mathrm{Ti}_{3} \mathrm{O}_{7}$}

Peng's group [13] indicated two possible formation mechanisms of $\mathrm{H}_{2} \mathrm{Ti}_{3} \mathrm{O}_{7}$. In their report, trititanate $\left(\mathrm{Ti}_{3} \mathrm{O}_{7}\right)^{2-}$ sheets may grow within the intermediate phase, caused by the reaction between $\mathrm{NaOH}$ and $\mathrm{TiO}_{2}$. The nanosheets grow with an increasing tendency of curling, leading to the formation of nanotubes. Also, $\mathrm{Na}_{2} \mathrm{Ti}_{3} \mathrm{O}_{7}$-like nanocrystal was postulated to form in this disorder-phase, and single trititanate layer subsequently peeled off from the nanocrystal and curved naturally likewood shavings into nanotube. This phenomenon was inferred from the excessive intercalation of $\mathrm{Na}^{+}$between the spaces of crystals. Their other studies reinforced the afore stated mechanism [14,15] where the hydrogen-deficiency on the surface of $\left(\mathrm{Ti}_{3} \mathrm{O}_{7}\right)^{2-}$ plates can provide the driving force (surface tension) for the peeling-off of $\left(\mathrm{Ti}_{3} \mathrm{O}_{7}\right)^{2-}$ plates and therefore resulting in the layers bent to form tube morphology. In their reports, the optimum dimension of TNTs has also been surveyed in terms of energy views. The number of layers within TNTs was subject to Coulomb energy, which was induced by the negatively charged $\left(\mathrm{Ti}_{3} \mathrm{O}_{7}\right)^{2-}$ layers. Coupling energy, resulting from the contributions of unequal distribution between two sides of $\left(\mathrm{Ti}_{3} \mathrm{O}_{7}\right)^{2-}$ layers and the usual elastic strain energy of bent crystalline plate, optimize the radius of TNTs at $4.3 \mathrm{~nm}$. At the same time, an atomic model for TNTs based on investigations with X-ray diffraction (XRD), highresolution transmission electron microscope (HR-TEM), and selected area electron diffraction (SAED) was also established
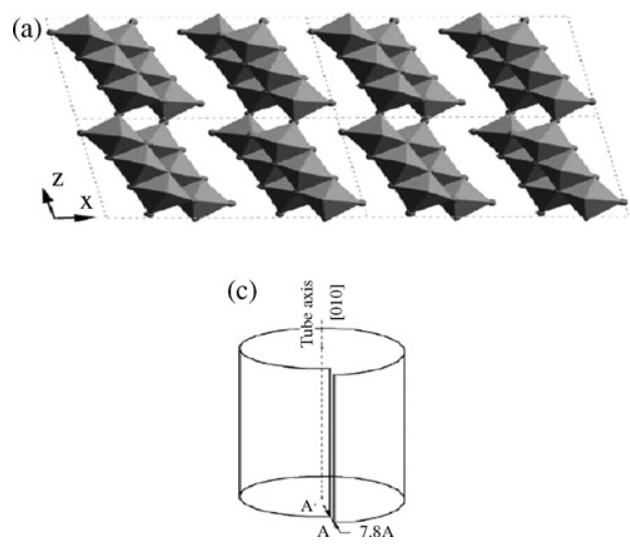

[14]. This report demonstrated that the tubes may be constructed by wrapping a ( 1000$)$ plane along $\mathrm{AA}^{\prime}$, as indicated in Fig. 3(b). Fig. 3(c) illustrates the construction of a nanotube by the displacement of $\mathrm{A}^{\prime}$ with a space of $0.78 \mathrm{~nm}$, and the structure and cross-sectional view of TNTs are shown in Fig. 3(a) and (d), respectively.

Special analytic methods, including ion conductivity and solid-state nuclear magnetic resonance (NMR), have been employed to investigate the thermal behavior of $\mathrm{H}_{2} \mathrm{Ti}_{3} \mathrm{O}_{7}$ and the distinguishable phenomenon between structural protons and trapped water [19]. Based on spectroscopic plots of conductivity measurements for $\mathrm{H}_{2} \mathrm{Ti}_{3} \mathrm{O}_{7}$ at temperatures of interest (30, 130 and $300{ }^{\circ} \mathrm{C}$ ), a less distributed response at high temperature was observed. This phenomenon was ascribed to the higher degree of crystallization in the sample after thermal treatment. The peaks obtained from NMR analysis for $\mathrm{H}_{2} \mathrm{Ti}_{3} \mathrm{O}_{7}$ after thermal treatment can be exclusively attributed to the contributions of structural proton and trapped $\mathrm{H}_{2} \mathrm{O}$. In separate studies, the amorphous regions can also be observed within TNTs structure because of defects during the formation process, including the inappropriate attachment between nanosheets, and the unsaturation of dangling bonds on the surfaces of lamellar sheets $[37,38]$.

\subsection{The group of $\mathrm{Na}_{x} \mathrm{H}_{2-x} \mathrm{Ti}_{2} \mathrm{O}_{4}(\mathrm{OH})_{2}$}

A postulate as to why the TNT structure can be assigned for the $\mathrm{Na}_{2} \mathrm{Ti}_{2} \mathrm{O}_{4}(\mathrm{OH})_{2}$ phase is provided by Yang et al. [16] where they thought it is impossible for the weak acid $\mathrm{H}_{2} \mathrm{Ti}_{3} \mathrm{O}_{7}$ to exist in concentrated $\mathrm{NaOH}$. Further results with regard to the dependence of $\mathrm{Na} / \mathrm{Ti}$ on $\mathrm{pH}$ values indicated that TNTs within an $\mathrm{H}^{+} / \mathrm{Na}^{+}$ratio of 4 can present good stability during hydrothermal treatment. For the lattice parameter of $\mathrm{H}_{2} \mathrm{Ti}_{2} \mathrm{O}_{4}(\mathrm{OH})_{2}$, the large elongation along the $a$ axis was ascribed to the layered structure of the material. Based on electron spin resonance (ESR) measurements, the optical characterizations of dehydrated nanotube $\mathrm{H}_{2} \mathrm{Ti}_{2} \mathrm{O}_{4}(\mathrm{OH})_{2}$ have also been studied by Zhang et al. [18]. They indicated the dependence of the concentration of single-electrontrapped oxygen vacancies $(g=2.003)$ on vacuum dehydration time increases the visible-light absorption power. This gives

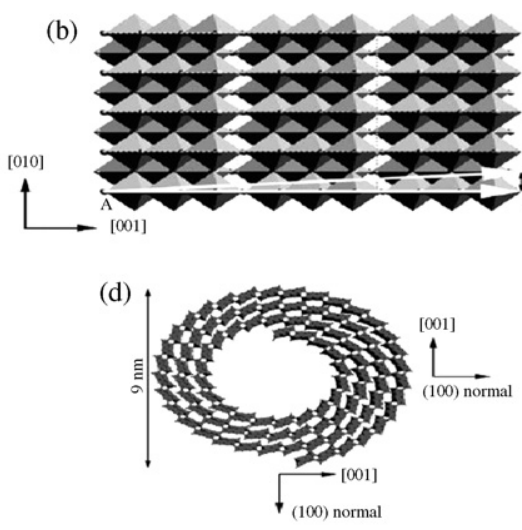

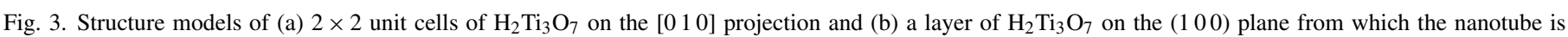

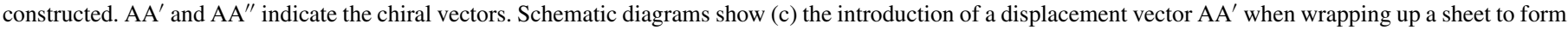
a scroll-type nanotube and (d) the structure of tritianate nanotubes. The crystal orientations indicated are the orientations according to the $\mathrm{H}_{2} \mathrm{Ti}_{3} \mathrm{O}_{7} \mathrm{layer}_{[14]}$. 


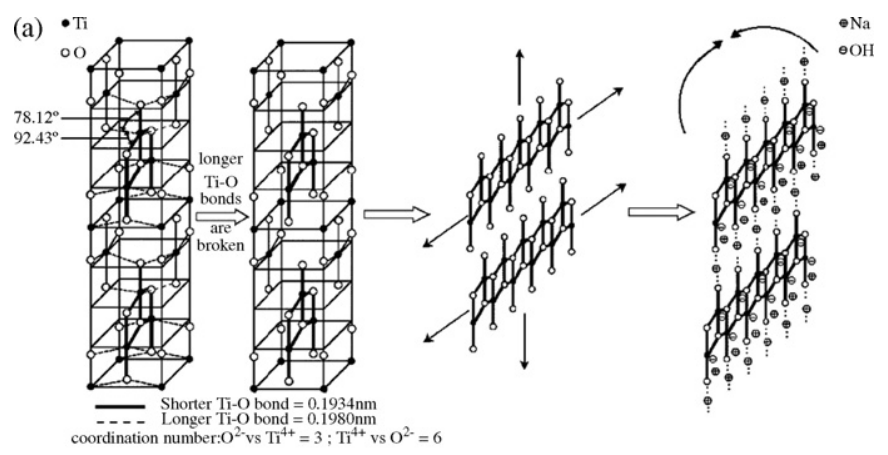

(b)

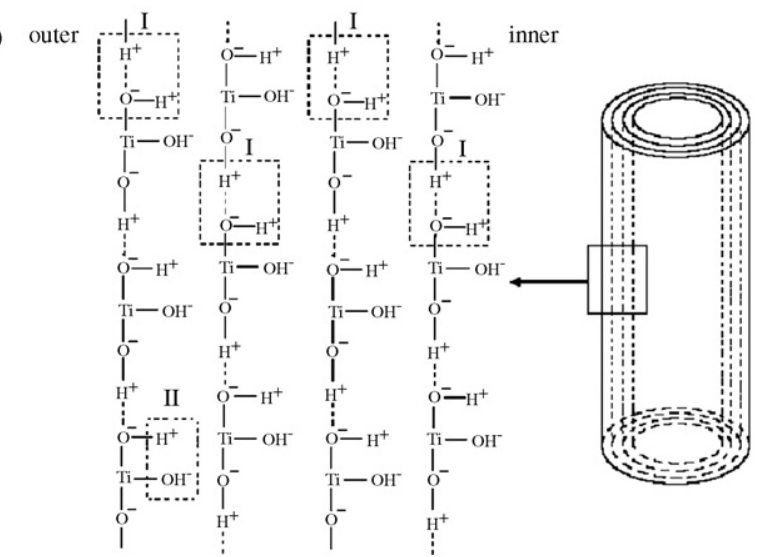

Fig. 4. Schematic diagrams: (a) formation process of $\mathrm{Na}_{2} \mathrm{Ti}_{2} \mathrm{O}_{4}(\mathrm{OH})_{2}$ and (b) mechanism for breaking of $\mathrm{Na}_{2} \mathrm{Ti}_{2} \mathrm{O}_{4}(\mathrm{OH})_{2}$ [18].

strong support for dehydrated nanotube $\mathrm{H}_{2} \mathrm{Ti}_{2} \mathrm{O}_{4}(\mathrm{OH})_{2}$ to be applied on some technological fields under visible light irradiation.

The formation mechanism of $\mathrm{Na}_{2-x} \mathrm{H}_{x} \mathrm{Ti}_{2} \mathrm{O}_{4}(\mathrm{OH})_{2}$ phase was also provided by Yang et al. [16], where the swell of $\mathrm{TiO}_{2}$ particles was considered as the initial stage. Swelling stripes and the peel-off of granules can subsequently be found based on the TEM observation, after which tube structure is formed. The detailed mechanism is as follows: the shorter Ti-O bonds within $\mathrm{TiO}_{6}$ units are expected to divide under the concentrated $\mathrm{NaOH}$ solution, and results in irregular swelling. The resulting linear fragments would link to each other by $\mathrm{O}^{-}-\mathrm{Na}^{+}-\mathrm{O}^{-}$ bonds to form flexible planar fragments. Nanotubes could be obtained through the covalent bonding of end groups, as indicated in Fig. 4(a). Fig. 4(b) describes the intralayer composition of $\mathrm{Na}_{2-x} \mathrm{H}_{x} \mathrm{Ti}_{2} \mathrm{O}_{4}(\mathrm{OH})_{2}$ after the replacement of $\mathrm{Na}^{+}$by $\mathrm{H}^{+}$ during acid washing. This mechanism was further emphasized by Tsai and Teng [21], who indicated that the replacement of $\mathrm{Na}^{+}$by $\mathrm{H}^{+}$cause a peeling-off of individual layers from $\mathrm{TiO}_{2}$ particles owing to the variation of the surface charge. Further supports, including the lattice parameters and some conclusions obtained from XRD results, related to the assignment for $\mathrm{Na}_{2}{ }_{-x} \mathrm{H}_{x} \mathrm{Ti}_{2} \mathrm{O}_{5}\left(\mathrm{H}_{2} \mathrm{O}\right)$ phase were also reported in this research. The energy defect caused by dangling bonds on the $\mathrm{TiO}_{2}$ layers must be compensated to stabilize the structure. Subsequently, the lamellar $\mathrm{TiO}_{2}$ bent to form non-concentric tube structures.

\subsection{Other supporting evidence in TNT formation}

In Kasuga's research [11], it was considered that the reaction of Ti-O-Na with acid would lead to the formation of sheets, along with a decrease in the length of $\mathrm{Ti}-\mathrm{O}-\mathrm{Ti}$ bonds. The residual electrostatic repulsion of $\mathrm{Ti}-\mathrm{O}-\mathrm{Na}$ bonds may cause a connection between $\mathrm{Ti}-\mathrm{O}-\mathrm{Ti}$ sheets and subsequently lead to the formation of tube structure. The oriented crystal growth pertaining to the formation of TNTs was also indicated by Kukovecz et al. [39]. Some materials were peeling off from anatase particles, leaving behind terraces on the surface, and re-crystallizing as trititanate sheets. These sheets subsequently curved into nanoloop, which was believed to be the seed in the formation process of TNTs, and the curvature of the loops determined the morphology of TNT cross sections giving rise to spiral, onion, and multiplespiral types. In a separate study, the rolling mechanism from nanosheets into nanotubes was also reported by Ma et al. [40], who indicated that the de-intercalation of $\mathrm{Na}$ ions caused by $\mathrm{H}_{3} \mathrm{O}^{+}$substitution would reduce the interaction between layered sheets. The topmost layer would peel off due to a reduction in electrostatic interaction with the underlying substrates and gradually curl up into tube structure. Another study highlighting the soft chemical reactions also proposed the related formation mechanism [41]. In this report, $\mathrm{Na}_{2} \mathrm{Ti}_{3} \mathrm{O}_{7}$, used as the Ti precursor instead of $\mathrm{TiO}_{2}$, was capable of synthesizing TNTs without the presence of $\mathrm{NaOH}$. It was also indicated that $\left[\mathrm{TiO}_{6}\right]$ layers can hold each other owing to the strong static interaction between $\left[\mathrm{TiO}_{6}\right]$ units within $\mathrm{Na}_{2} \mathrm{Ti}_{6} \mathrm{O}_{13}$. The replacement of $\mathrm{Na}^{+}$by $\mathrm{H}_{2} \mathrm{O}$ during hydrothermal treatment would weaken the static interaction, resulting in the exfoliation of $\left[\mathrm{TiO}_{6}\right]$ layers from $\mathrm{Na}_{2} \mathrm{Ti}_{6} \mathrm{O}_{13}$ particles. An intrinsic extension existed owing to the inversion symmetry of these sheets which led to the curling process into tube structure.

\section{Effects of fabrication factors in TNT fabrication}

Applied temperature, treatment time, the type of alkali solution, and the Ti precursor are considered as the predominant factors in TNT fabrication during hydrothermal treatment. It has been established that the dependence of morphology and features of TNTs on hydrothermal conditions significantly dominates the corresponding characterizations of TNTs. Therefore, it is essential to assemble related results and construct a welldefined conclusion.

\subsection{Applied temperature and treatment duration}

Seo et al. [42] revealed that the amount and length of TNTs gradually increase with applied temperatures $\left(100-200^{\circ} \mathrm{C}\right)$, where the largest specific surface area along with the larger inner diameter of TNTs emerged at synthesis temperature of $150^{\circ} \mathrm{C}$. In a separate study, pore structure of TNTs relevant to the applied temperature and the concentration of acid-washing, was also reported by Tsai and Teng [20]. In the case of temperatures ranging from 110 to $150^{\circ} \mathrm{C}$, the maximum pore volume and surface area occurred for TNTs synthesized at $130^{\circ} \mathrm{C}$. A reasonable concept was proposed that temperatures lower 
than $130^{\circ} \mathrm{C}$ led to less cleavage of Ti-O-Ti bonds, which was the initial stage in synthesizing TNTs. Treatment at high temperature $\left(>130^{\circ} \mathrm{C}\right)$ would destroy the lamellar $\mathrm{TiO}_{2}$, an intermediate in the TNTs formation process. Poudel et al. [25] first related the filling fraction and pressure of autoclave to the characterizations of TNTs. Either case of filling fraction or acid washing governs the performance of crystallization, where the optimum filling fraction ( $86 \%$ to the vessel volume) and $0.1 \mathrm{~N} \mathrm{HCl}$ were reported to be capable of good crystalline formation.

\subsection{Applied alkali solute and Ti precursors}

The effects of $\mathrm{NaOH}$ concentration, applied temperature, and precursors (Degussa P25, anatase and amorphous $\mathrm{TiO}_{2}$ ) on the TNT formation have also been investigated by Yuan and $\mathrm{Su}$ [43], who concluded that the hydrothermal temperature at $100-160^{\circ} \mathrm{C}$ results in the production of TNTs; Nanofiber was found being $\mathrm{H}_{2} \mathrm{Ti}_{3} \mathrm{O}_{7}$ phase when amorphous $\mathrm{TiO}_{2}$ was used as the precursor. Moreover, nanoribbons occurred at the $\mathrm{NaOH}$ concentration of $5-15 \mathrm{~N}$ under the temperature range of $180-250{ }^{\circ} \mathrm{C}$, which was assigned for the $\mathrm{H}_{2} \mathrm{Ti}_{5} \mathrm{O}_{11}\left(\mathrm{H}_{2} \mathrm{O}\right)$ phase. Nanowires formed exclusively at the solution of $\mathrm{KOH}$ and were indexed as $\mathrm{K}_{2} \mathrm{Ti}_{8} \mathrm{O}_{7}$, whereas nanowires were obtained in the LiOH treated samples. Non-hollow nanofibers/nanoribbons were also reported in an apparently similar hydrothermal procedure [44]. A ribbon-like structure with the width of 30-200 nm was obtained under the hydrothermal conditions of $10 \mathrm{~N} \mathrm{NaOH}$ for $24 \mathrm{~h}$ at $200^{\circ} \mathrm{C}$. These nanoribbons were evidenced to be anatase $\mathrm{TiO}_{2}$ [44]. The role of $\mathrm{Na}$ atoms in fabrication processes has been investigated by Chen et al. [13]. In their results, TNTs formed exclusively in the presence of $\mathrm{Na}$ atom while nanorods/plates and nanoparticles were observed in the $\mathrm{KOH}$ and $\mathrm{LiOH}$ reacted samples.

Many studies indicated that the anatase phase was the preferred phase with higher surface energy in synthesizing TNTs $[20,45]$. This was also confirmed based on the crystalline characteristics [42,46]. Comparatively, Tsai and Teng [21] have elucidated that rutile phase would be more vigorous than anatase phase in the rearrangement, which was the intermediate stage to form TNTs. For the rutile phase as the precursor of TNTs, the increasing hydrothermal temperature and duration can result in single-crystalline nanorods with excellent thermal stability [47].

\subsection{The effect of acid washing}

Despite Kasuga et al. [11] tentatively proposed that acidwashing was one step of the formation process of TNTs, following researches have suggested acid-washing just for the ion exchangeable process $[12,47]$. Even though the formation mechanism is still ambiguous, the acid-washing process appreciably affects the attributes of TNTs owing to the relative amount of $\mathrm{Na}$ and $\mathrm{H}$ atoms within TNT structure. Acid washed TNTs are believed to possess more intercalated $\mathrm{H}_{2} \mathrm{O}$ than non-acid washed TNTs, and subsequently result in greater weight loss during thermal gravimetric analysis (TGA) spectrum [31]. In terms of the pore structure of TNTs, an optimum concentration of $\mathrm{HCl}$ $(0.2 \mathrm{~N})$ during the washing process was suggested because the rapid removal of electrostatic charges caused by high acid concentration is detrimental to the formation of TNTs [20]. Their following research demonstrated the same results where the tplot method and density function theory were utilized to explain the pore structure of TNTs treated by $\mathrm{HCl}$ under various $\mathrm{pH}$ [23]. Either critical pore diameter or external surface area obtained from the aforesaid analytic methods responded to the surface area and pore volume, and evidenced the effect of acid-washing on the structure of TNTs more clearly. Yang et al. [16] discovered the phenomenon of replacement of $\mathrm{Na}^{+}$in $\mathrm{Na}_{2} \mathrm{Ti}_{2} \mathrm{O}_{4}(\mathrm{OH})_{2}$ by $\mathrm{H}^{+}$. This notion was reinforced by Nian and Teng [22], who demonstrated a similar behavior in XRD patterns and that the ratio of peak $110-310$ is convinced as being the evidence of the displacement of $\mathrm{Na}^{+}$by $\mathrm{H}^{+}$. Similar XRD patterns have also been demonstrated in other studies, even though they preferentially assigned the obtained TNTs to $\mathrm{Na}_{x} \mathrm{H}_{2-x} \mathrm{Ti}_{3} \mathrm{O}_{7}[48,49]$. Weng et al. [48] indicated that hydrogen-TNTs exhibited a broad peak from $2 \theta=23^{\circ}$ to $25^{\circ}$ while another characteristic peak appear at $28^{\circ}$ for sodium-TNTs. Systematic study associated with the stability and structure of TNTs as a function of $\mathrm{Na}$ content has also been investigated in detail by Morgado et al. [49]. This report demonstrated that the interlayer spacing of TNTs increases with more intercalated $\mathrm{Na}$ amount, which also aids the stability of TNTs during thermal treatment. The behavior of water re-absorption of TNTs with an abundant Na amount was also proved based on the TGA experiment. The crystal composition of TNTs after thermal treatment was determined by Rietveld analysis, which indicated that TNTs with low $\mathrm{Na}$ content causes crystallization of $\mathrm{TiO}_{2}$ with anatase phase and brookite phase. An increase in Na content within the TNT structure results in another re-crystallization pathway to form $\mathrm{Na}_{2} \mathrm{Ti}_{3} \mathrm{O}_{7}$ and $\mathrm{Na}_{2} \mathrm{Ti}_{6} \mathrm{O}_{13}$. The performance of BET surface area $\left(\mathrm{S}_{\mathrm{BET}}\right)$ is also subject to the intercalating amount of $\mathrm{Na}$ atoms, for which the collapse of tube structure occurred earlier and more drastically for TNTs with a low Na amount.

\section{Post-treatments of TNTs}

In many investigations directed towards post-treatments of TNTs to achieve the activity of TNTs with the intention of comprehensive applications, post-thermal treatment received more attention than other treatments. In attempts at the investigation of the crystalline phase for thermally treated TNTs, the presence of $\mathrm{Na}$ atoms within TNT structure was significantly responsible for the corresponding thermal behavior [31]. Yoshida et al. [50] also reported a similar phenomenon where some nanotubes began to break and condensed into particles of anatase phase at temperatures higher than $350^{\circ} \mathrm{C}$, and others with a large quantity of $\mathrm{Na}$ remained as nanotube. $\mathrm{Na}$ atoms within TNT structure dominate the formation of Na-included crystallization while proton-TNTs proceed with another recrystalline pathway to form anatase phase or even rutile phase. 


\subsection{Phase structure and pore structure of TNTs after thermal treatment}

Investigations pertaining to the overall effect of thermal treatment on TNTs have been conducted by many researches. Predominant phases including $\mathrm{TiO}_{2}$ (brookite), $\mathrm{TiO}_{2}$ (anatase), $\mathrm{TiO}_{2}$ (rutile), $\mathrm{Na}_{2} \mathrm{Ti}_{3} \mathrm{O}_{7}, \mathrm{Na}_{2} \mathrm{Ti}_{6} \mathrm{O}_{13}$, etc. for TNTs after thermal treatment have been demonstrated. Suzuli and Yoshikawa [51] found the existence of $\mathrm{TiO}_{2}$ (B) free of anatase after the thermal treatment of TNTs while Armstrong et al. [52] also observed $\mathrm{TiO}_{2}$ (B) for their nanowires after thermal treatment of TNTs at $400-600^{\circ} \mathrm{C}$. Poudel et al. [25] indicated that the rutile phase begin to crystallize at $800{ }^{\circ} \mathrm{C}$, well below the transformation temperature of $925^{\circ} \mathrm{C}$ for bulk anatase $\mathrm{TiO}_{2}$ nanopowder. Also, a change from nanotubes to nanowire morphology was observed at the annealed temperature of $650^{\circ} \mathrm{C}$. Further comparisons in this research also present that TNTs are less stable under oxygen than under vacuum, although still more stable than TNTs fabricated by electrochemistry anodic oxidation. In other reports, the onset of anatase to rutile transformation was also reported at $700{ }^{\circ} \mathrm{C}$ by $\mathrm{Yu}$ et al. [53], while another research provided it at $900^{\circ} \mathrm{C}$ [20]. Tsai and Teng [20] also indicated that the temperature for anatase to rutile transformation was relevant to the synthesis temperature of TNTs where such transformation occurred at $900^{\circ} \mathrm{C}$ while TNTs was synthesized at $130^{\circ} \mathrm{C}$. When TNTs were calcined at $600^{\circ} \mathrm{C}$, Na-containing species of $\mathrm{Na}_{2} \mathrm{Ti}_{9} \mathrm{O}_{19}$ emerges and thereafter transforms as $\mathrm{Na}_{2} \mathrm{Ti}_{6} \mathrm{O}_{13}$ and $\mathrm{TiO}_{2}$ at $800^{\circ} \mathrm{C}$ [31]. Tsai and Teng [21] suggested that $\mathrm{Na}_{2} \mathrm{Ti}_{6} \mathrm{O}_{13}$ within a tunnel structure can behave as a high thermal insulation with chemical stability; therefore, it can be used as potential adiabatic materials. The result was further evidenced in the following reports $[49,50,54]$. While thermal temperature is higher than $300^{\circ} \mathrm{C}$, amorphous phase can be observed and is ascribed to the dehydration of the intralayered $\mathrm{OH}$ group within TNTs [18]. Further explanation in terms of mass-transport of atoms within TNTs during thermal treatment was also demonstrated. In this report, it was indicated that the morphology was changed to a rod-like one for which the length was relevant to the amount and distribution of defects, contributed by the dehydration of the $\mathrm{OH}$ group. Another contribution provided by Nian and Teng [22] indicated that the rod formation was ascribed to the oriented attachment of adjacent TNTs together with the local shrinkage of the TNTs during thermal treatment. Systematic studies concerning the reversible transitions of crystal phase by different treatments have also been conducted [55]. In fact, the crystal phase and morphology change of TNTs after thermal treatment are significantly relevant to the amount of $\mathrm{Na}$ atoms intercalated with TNTs, as indicated in Fig. 5.

The textural parameters from the adsorption-desorption isotherm data for TNTs after thermal treatment were also examined by $\mathrm{Yu}$ et al. [56]. The specific surface and pore volume decrease with increasing calcination temperature, suggesting the collapse of tube structure. They also indicated that the advantage of high pore volume and specific surface area can be preserved until the calcinations temperature reached $600^{\circ} \mathrm{C}$. However, the pore size of TNTs increases to $44.8 \mathrm{~nm}$ at $700{ }^{\circ} \mathrm{C}$ and then dramatically decreases to $8.2 \mathrm{~nm}$ at $800^{\circ} \mathrm{C}$; This phenomenon was

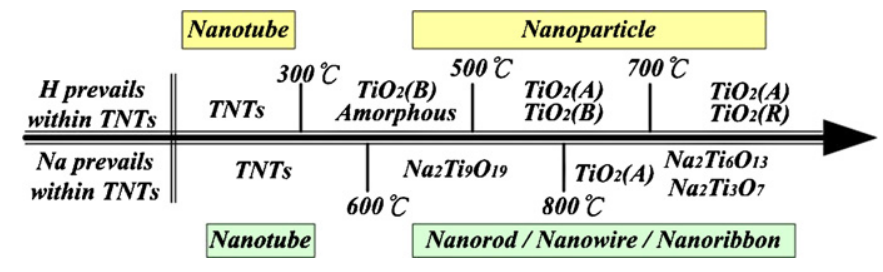

Fig. 5. Possible crystal phases and morphologies of TNTs after thermal treatment.

attributed to the collapse of small pores inside TNTs and the growing crystallization of $\mathrm{TiO}_{2}$. In another conclusion [20], the high porosity in TNTs was also reported to disappear after thermal treatment at $600{ }^{\circ} \mathrm{C}$. Beside the aforementioned investigation, the optical property of thermally treated TNTs was also studied by Wang et al. [33]. The hydration and nano-sized effect caused the blue shift of TNTs whose absorption edge was $342 \mathrm{~nm}$ while that of bulk anatase $\mathrm{TiO}_{2}$ was $385 \mathrm{~nm}$. The visible absorption of thermally treated TNTs resulting from the growth of new crystallization, $\mathrm{Ti}_{5} \mathrm{O}_{9}$ and anatase $\mathrm{TiO}_{2}$ was enhanced with increasing temperatures of $400-600{ }^{\circ} \mathrm{C}$.

\subsection{Other post-treatments of TNTs}

While thermal treatment of TNTs displays beneficial effects on photocatalytic ability, it is detrimental to the physical aspects of TNTs such as BET surface area and pore volume. Therefore, researchers are also looking into alternative methods to increase the activity of TNTs without the undesirable effect of pore blockage to avoid the elimination of surface $\mathrm{OH}$ group and to stabilize tube morphology during thermal treatment. However, so far, far too few post-treatments were successful or well developed.

Bavykin et al. [32] have investigated the structural change of acid-immersed TNTs after a series of treatment periods. They indicated there were three stages for structural change of TNTs during the immersion process; (1) erosion and disruption of TNT structure, (2) the formation of rutile nanoparticles and $\mathrm{H}_{2} \mathrm{Ti}_{3} \mathrm{O}_{7}$ phase, and (3) stable rutile phase along with trace amount of TNTs were present. Meanwhile, the results derivated from that of concentrated acid and thermal treatment were ascribed to the lower rate of phase change, and this report suggested that these can be promising candidates to obtain rutile phase. The posthydrothermal treatment of TNTs has also been investigated by Nian and Teng [22]. The characterization of treated TNTs is subject to the applied $\mathrm{pH}$ conditions; only anatase phase appears at $\mathrm{pH} 2.2$ while anatase along with brookite can be observed at $\mathrm{pH}$ 8.2. Rod morphology was found exclusively for TNTs treated at $\mathrm{pH}$ 5.6, which was also assigned for anatase phase. Crystal enlargement with $\mathrm{pH}$ values is anisotropic and the condition at $\mathrm{pH} 5.6$ makes the maximum enlargement degree result in rod formation. Similar research emphasizing the phase structure, morphology, and pore structure has also been investigated [56]. In this research, fiber-like structure with anatase phase can be observed after post-hydrothermal treatment. Furthermore, the growth of $\mathrm{TiO}_{2}$ crystallites with increasing post-hydrothermal treatment time was evidenced to be responsible for a small distribution of pore size, a decrease in pore volume and average pore 
Table 3

Recent studies concerning the morphology and crystal phase of TNTs after post-treatment

\begin{tabular}{|c|c|c|}
\hline Post-treatment & Reference & Observed results \\
\hline \multirow{10}{*}{ Post-thermal treatment } & Yoshida et al. [50] & $\begin{array}{l}\text { Some nanotubes began to break into particles of anatase phase at temperature higher than } \\
350^{\circ} \mathrm{C} \text { while the others remained as nanotube with the presence of a large quantity of } \mathrm{Na}\end{array}$ \\
\hline & Suzuli et al. [51] & The existence of $\mathrm{TiO}_{2}$ (B) free of anatase during thermal treatment of TNTs \\
\hline & Armstrong et al. [52] & $\mathrm{TiO}_{2}$ (B) with nanowires morphology after thermal treatment of TNTs at $400-600^{\circ} \mathrm{C}$ \\
\hline & Poudel et al. [25] & $\begin{array}{l}\text { Rutile phase begin to crystallize at } 800^{\circ} \mathrm{C} \text {; nanotubes to nanowire morphology was } \\
\text { observed at the annealed temperature of } 650^{\circ} \mathrm{C}\end{array}$ \\
\hline & Tsai and Teng. [20] & Anatase to rutile transformation was reported at $900^{\circ} \mathrm{C}$ \\
\hline & Yu et al. [53] & Anatase to rutile transformation was reported at $700^{\circ} \mathrm{C}$ \\
\hline & Sun and $\mathrm{Li}[31]$ & $\mathrm{Na}_{2} \mathrm{Ti}_{9} \mathrm{O}_{19}$ emerges at $600^{\circ} \mathrm{C}$ and thereafter transforms as $\mathrm{Na}_{2} \mathrm{Ti}_{6} \mathrm{O}_{13}$ and $\mathrm{TiO}_{2}$ at $800^{\circ} \mathrm{C}$ \\
\hline & Zhang et al. [18] & Amorphous phase emerges at thermal temperature higher than $300^{\circ} \mathrm{C}$ \\
\hline & Yu et al. [56] & $\begin{array}{l}\text { Pore volume and specific area of TNTs can be preserved until the calcinations temperature } \\
\text { achieved } 600{ }^{\circ} \mathrm{C}\end{array}$ \\
\hline & Wang et al. [33] & $\begin{array}{l}\text { The visible absorptions of thermal treated TNTs were enhanced with increasing } \\
\text { temperatures of } 400-600^{\circ} \mathrm{C}\end{array}$ \\
\hline \multirow[t]{2}{*}{ Post-hydrothermal treatment } & Nian and Teng [22] & The $\mathrm{pH}$ values during hydrothermal treatment dominates the corresponding behavior \\
\hline & Yu et al. [56] & $\begin{array}{l}\text { Fiber-like structure with anatase phase was observed; Increasing treatment time dominate } \\
\text { the pore structure of TNTs }\end{array}$ \\
\hline Acid immersion process & Bavykin et al. [32] & Stable rutile phase formed owing to the low rate in phase change \\
\hline Electrodeposition process & Kim et al. [58] & TNTs were fabricated as thin film without the presence of $\mathrm{Na}$ atoms \\
\hline Hot filament chemical vapor deposition & Godbole et al. [60] & Different treatment conditions results in the different crystal phase \\
\hline
\end{tabular}

diameter. Regular multi-layer films of TNTs have been fabricated in a sequential layer-by-layer assembly with polycations [57]. An approximately equal amount of TNTs was deposited for each layer pair in the fabrication process, which provided a criterion, as far as this deposition method was concerned, for the stepwise and regular film growth process. For another deposition method, TNTs coated on silicon substrates by the electrodeposition process has also been demonstrated by Kim et al. [58,59]. Their observation indicated that electrodeposited coating resulted in negligible or zero concentration of sodium; further study based on X-ray photoelectron spectroscope (XPS) determinations showed that the reduction of strongly bonded sodium can be achieved by electrodeposition process while acid treatment just provided the ability to remove weakly bonded sodium. A point worthy of mentioning is that TNTs can inherit its tube morphology via electrodeposition process as a thin film, which is desirable for practical applications. The results of their following research associated with the characterizations of coated TNTs after some processing was also demonstrated [60]. Coated TNTs processed by hot filament chemical vapor deposition (HF-CVD) under various conditions presents significantly different results. Atmospheric/vacuum processing result in the rutile and anatase phase; no characteristic phase was observed after plasma treatment. In the case of $\mathrm{H}_{2} / \mathrm{CH}_{4}$ mixing gas, some composite phases can be observed including rutile phase $\left(\mathrm{TiO}_{2}\right)$, non-stoichiometric phases $\left(\mathrm{Ti}_{2} \mathrm{O}_{3}\right.$ and $\left.\mathrm{Ti}_{3} \mathrm{O}_{5}\right)$, titanium carbide, and extensive carbon nanowires and nanotubes. All the aforementioned studies concerning the post-treatments of TNTs are shown in Table 3.

\section{Modifications of hydrothermal treatment}

In spite of the previous discussions in favor of the synthesis of TNTs for its excellent morphology, some limitations for TNTs as advanced materials emerge owing to their low crystalline content. To inherit or regain the activity from the precursor, further modifications in hydrothermal treatment were required. Also, with an aim to shorten the long duration in synthesizing TNTs, some assisted methods have been developed to enhance the formation kinetic of TNTs. The authors have categorized two broad groups, namely, chemical modification and physical modification to discuss related reports, as indicated in Table 4 .

\subsection{Chemical modification}

Nanorods can be formed by surface modification of $n$ octadecytrichlorosilane (OTS) in hydrothermal treatment [61]. A possible explanation was also provided that OTS can hydrolyze then be adsorbed onto the surface of TNTs, along with the coverage of hydrophobic group onto the surface of TNTs. The resulting TNTs can aggregate themselves to form thinner rods, and further aggregation can result in thinner ones. Another study indicating the presence of $\mathrm{Zn}^{2+}$ in hydrothermal treatment would cause the formation of layered $\mathrm{H}_{2} \mathrm{Ti}_{2} \mathrm{O}_{5}\left(\mathrm{H}_{2} \mathrm{O}\right)$ nanosheets [34]. TNTs with ultrahigh crystallization can be obtained after $\mathrm{H}_{2} \mathrm{O}_{2}$ treatment under reflux at $40^{\circ} \mathrm{C}$ for $4 \mathrm{~h}$ [45]. This report indicated that the oxygen vacancies can be compensated by $\mathrm{H}_{2} \mathrm{O}_{2}$, as being supported by some measurements including XRD, HRTEM, and photoluminescence (PL). Especially the blue shift of $\mathrm{H}_{2} \mathrm{O}_{2}$-modified TNTs suggested the recovery of oxygen vacancies of TNTs after treatment with $\mathrm{H}_{2} \mathrm{O}_{2}$. Meanwhile, the intensity of anatase phase for $\mathrm{H}_{2} \mathrm{O}_{2}$ modified TNTs can be drastically enhanced due to the presence of $\mathrm{H}_{2} \mathrm{O}_{2}$. Another related study demonstrated that the presence of $\mathrm{H}_{2} \mathrm{O}_{2}$ in $\mathrm{NaOH}$ solution at a temperature of $220^{\circ} \mathrm{C}$ for $48 \mathrm{~h}$ can be developed as the ordered array of titanate with aspect ratios of 20,000 [62], which was the first report regarding the development of titanate nanowire arrays via hydrothermal treat- 
Table 4

Recent techniques used to modify hydrothermal treatment

\begin{tabular}{|c|c|c|}
\hline Reference & Techniques used & Contributions \\
\hline \multicolumn{3}{|l|}{ Chemical modification } \\
\hline Zhang et al. [61] & $\begin{array}{l}\text { The presence of } n \text {-octadecytrichlorosilane during } \\
\text { hydrothermal treatment }\end{array}$ & The formation of nanorods \\
\hline Song et al. [34] & The presence of $\mathrm{Zn}^{2+}$ during hydrothermal treatment & The formation of nanosheets \\
\hline Khan et al. [45] & The presence of $\mathrm{H}_{2} \mathrm{O}_{2}$ under refluxing at $40^{\circ} \mathrm{C}$ for $4 \mathrm{~h}$ & The intensity of anatase was drastically enhanced \\
\hline Kim et al. [58] & Electrophoretic deposition & $\begin{array}{l}\text { The sodium content within TNTs was reduced } \\
\text { drastically in electrodeposition process }\end{array}$ \\
\hline Zhao et al. [62] & $\begin{array}{l}\text { The presence of } \mathrm{H}_{2} \mathrm{O}_{2} \text { during hydrothermal treatment at } \\
220 \text { for } 48 \mathrm{~h}\end{array}$ & The formation of ordered arrays of TNTs \\
\hline Weng et al. [48] & $\begin{array}{l}\mathrm{Na}_{2} \mathrm{Ti}_{3} \mathrm{O}_{7} \text { was used as the Ti precursor during } \\
\text { hydrothermal treatment }\end{array}$ & TNTs can be obtained without the presence of $\mathrm{NaOH}$ \\
\hline Kukovecz's group $[63,64]$ & The presence of $\mathrm{Na}_{2} \mathrm{~S}$ during hydrothermal treatment & $\begin{array}{l}\text { Resulting in the formation of CdS nanoparticles/TNTs } \\
\text { nanocomposites }\end{array}$ \\
\hline Ren et al. [65] & $\begin{array}{l}\text { The presence of thiourea and urea during hydrothermal } \\
\text { treatment }\end{array}$ & $\begin{array}{l}\text { The formation of } \mathrm{S}-\mathrm{TiO}_{2} \text { and } \mathrm{N}-\mathrm{TiO}_{2} \text { with dandelion } \\
\text { morphology }\end{array}$ \\
\hline \multicolumn{3}{|l|}{ Physical modification } \\
\hline Zhu et al. [66] & Sonic-assisted hydrothermal treatment & The formation kinetics of TNTs was enhanced \\
\hline Ma et al. [67] & Sonic-assisted hydrothermal treatment & The formation kinetics of TNTs was enhanced \\
\hline Wang et al. [68] & Microwave-assisted hydrothermal treatment & The formation kinetics of TNTs was enhanced \\
\hline Wu et al. $[27,28]$ & Microwave-assisted hydrothermal treatment & The formation kinetics of TNTs was enhanced \\
\hline
\end{tabular}

ment. These authors also assumed the nanowires grow along a perpendicular direction to form arrays. Soft chemical reaction has also been reported where TNTs can be found without the presence of $\mathrm{NaOH}$ when $\mathrm{Na}_{2} \mathrm{Ti}_{3} \mathrm{O}_{7}$ instead of $\mathrm{TiO}_{2}$ was used as the Ti precursor [48]. In their demonstration, TEM observations and pore size distribution presented that TNTs exhibited excellent homogeneous distribution. Also, the length of TNTs increases with a prolonged treatment period.

Kukovecz's group [63] has modified the precursor as a mixing solution of $\mathrm{Na}_{2} \mathrm{~S} / \mathrm{NaOH}$ to synthesize $\mathrm{CdS} / \mathrm{TNT}$ nanocomposites. Two steps were first reported in this fabrication, but they made a modification for the fabrication to be conducted as a one-step process [64]. They indicated that the uniform particle size and high tube coverage of $\mathrm{CdS}$ nanoparticles were contributed by the homogeneous solution phase of the Cd-EDTA complex. The measured CdS diameter in these two studies fell into the range of 3-9 and 2.4-8.4 nm, respectively. A separate study showed that doped $\mathrm{S}-\mathrm{TiO}_{2}$ and $\mathrm{N}-\mathrm{TiO}_{2}$ with dandelion morphology can also be fabricated in the presence of thiourea and urea during hydrothermal treatment [65]. These samples exhibited excellent stability and even subjected their slurry to ultrasonication for $1 \mathrm{~h}$, in which the strong chemical bonding between contacting lateral surfaces at the inner ends of rods was inferred to contribute to stability. The doped $\mathrm{TiO}_{2}$ nanodandelion with rutile phase also demonstrated photocatalytic activity to methylene blue degradation.

\subsection{Physical modification}

It is inevitable to allow at least $20 \mathrm{~h}$ for hydrothermal treatment with intention to achieve a high level of crystallization in TNTs, so it is important to consider other effective candidates to shorten the synthesis duration. However, so far, few researches have been dedicated to rapid kinetics in TNT formation. Zhu et al. [66] have proposed a technology coupled with sonication and hydrothermal treatment in which the synthesis duration is shortened from 20 to $4 \mathrm{~h}$. A similar result has been evidenced by Ma et al. [67]. To best of acknowledge, Zhang's group [68] discovered that TNT structure can be rapidly achieved with the aid of microwave irradiation, and a similar result was subsequently revealed by Wu et al. [27]. The effects of treatment time, concentration of $\mathrm{NaOH}$, applied irradiation power, and Ti precursors on the characterization of TNTs were subsequently investigated [28]. Both reports indicated that the chemical structure of TNTs is assigned for anatase $\mathrm{TiO}_{2}$. Regarding the effect of irradiation power on the formation of TNT structure, the formation kinetics is only enhanced under optimum irradiation power while overload of that would resolve and destroy the crystallization [28]. Potassium titanate nanowires have also been fabricated by microwave-assisted hydrothermal treatment conducted by Zhang's group [69]. A plausible explanation has also been proposed that microwave is capable of changing the polarization of hydroxyl species on the surface of the solid, facilitating reaction between solid and liquid.

\section{Applications of TNTs and TNT-derived materials}

Of the TNT materials being developed for various applications, many investigations have emphasized photocatalysis. The synthesized TNTs, unfortunately, generally do not inherit photocatalystic ability from the anatase phase of $\mathrm{TiO}_{2}$. A suitable and feasible method to regain the photocatalytic ability is the post-thermal-treatment, and many studies in this regard have acquired well-established conclusions. Moreover, applications on support/carriers, ion-exchange/adsorption, photochemistry, dry sensitized solar cells, and other prominent applications are also discussed in the following materials and compiled in Table 5. 
Table 5

Applications of TNTs on versatile aspects

\begin{tabular}{|c|c|c|c|}
\hline Reference & Treatment & Applications & Performance \\
\hline \multicolumn{4}{|l|}{ Support/carrier } \\
\hline Wang et al. [35] & Support of benzoic acid & Dispersion capacity & $\begin{array}{l}\text { Benzoic acid can dispersed as monolayer dispersion on the } \\
\text { surface of TNTs with the utmost capacity of } 0.55 \mathrm{~g} \mathrm{BA} \mathrm{g}^{-1} \\
\text { TNTs }\end{array}$ \\
\hline Idakiev et al. [74] & Au-supported TNTs & WGS reaction & $\begin{array}{l}\text { Reaction rate is increased than that of } \mathrm{Au} / \mathrm{Al}_{2} \mathrm{O}_{3} \text { by a factor } \\
\text { of } 4\end{array}$ \\
\hline Chien et al. [75] & $\mathrm{Pt} / \mathrm{Au}$-supported TNTs & $\mathrm{CO}_{2}$ hydorgention & $\begin{array}{l}\text { Reaction rate increased than that of } \mathrm{Pt} / \mathrm{Au} \text {-supported } \mathrm{TiO}_{2} \\
\text { by a factor of } 1-30\end{array}$ \\
\hline Tsai and Tang [20] & $\begin{array}{l}\mathrm{Cu} \text {-supported TNTs/thermal } \\
\text { treated }\end{array}$ & NO conversion & $\begin{array}{l}\text { Reaction rate is increased than that of } \mathrm{P} 25 \mathrm{TiO}_{2} \text { by a factor } \\
\text { of } 4\end{array}$ \\
\hline Nakahira et al. [77] & Pt-entrapped TNTs & HCHO conversion & $\begin{array}{l}\mathrm{Pt} / \mathrm{TNT} \text { s posses the comparative photocatalytic ability with } \\
\mathrm{TiO}_{2}\end{array}$ \\
\hline \multicolumn{4}{|l|}{ Photocatalytic degradation } \\
\hline Yu et al. [53] & Thermal treated TNTs & Acetone & $\begin{array}{l}\text { Reaction rate of treated TNTs at } 300-600{ }^{\circ} \mathrm{C} \text { is increased } \\
\text { than that of } \mathrm{P} 25 \mathrm{TiO}_{2} \text { by a factor of } 3-4\end{array}$ \\
\hline $\mathrm{Xu}$ et al. [71] & Zn surface-doped TNTs & Methyl organic & $\begin{array}{l}\text { Reaction rate of thermal treated } \mathrm{Zn} / \mathrm{TNTs}\left(400-500^{\circ} \mathrm{C}\right) \text { is } \\
\text { increased than that of } \mathrm{TiO}_{2} \text { nanoparticles by a factor } 2-3\end{array}$ \\
\hline Zhang et al. [17] & Thermal treated TNTs & Propylene & Reaction rate of treated TNTs is inferior to that of $\mathrm{P} 25 \mathrm{TiO}_{2}$ \\
\hline Song et al. [34] & $\mathrm{H}_{2} \mathrm{Ti}_{2} \mathrm{O}_{5}\left(\mathrm{H}_{2} \mathrm{O}\right)$ nanosheets & Methyl organic & $\begin{array}{l}\text { Reaction rate is similar to that of } \mathrm{TiO}_{2} \text { but larger than that } \\
\text { of } \mathrm{ZnO} \text { by a factor of } 1.5\end{array}$ \\
\hline Zhu et al. [55] & Thermal treated TNTs & Surforhodamine & $\begin{array}{l}\text { Reaction rate of TNTs is larger than that of } \mathrm{P} 25 \mathrm{TiO}_{2} \text { by a } \\
\text { factor of } 2\end{array}$ \\
\hline Khan et al. [45] & $\mathrm{H}_{2} \mathrm{O}_{2}$ modified TNTs & Trimethylamine & $\begin{array}{l}\text { Reaction rate of } \mathrm{H}_{2} \mathrm{O}_{2}-\text { TNTs is larger than that of TNTs by } \\
\text { a factor of } 2\end{array}$ \\
\hline Yu et al. [53] & Thermal treated TNTs & Aceton & $\begin{array}{l}\text { Reaction rate of TNTs treated at } 200^{\circ} \mathrm{C} \text { for } 7 \mathrm{~h} \text { is larger } \\
\text { than that of } \mathrm{P} 25 \mathrm{TiO}_{2} \text { by a factor of } 1.5\end{array}$ \\
\hline Gao et al. [72] & Thermal treated TNTs & Pentachlorophenol & $\begin{array}{l}\text { Reaction rate TNTs treated at } 400 \text { is larger than that of } \mathrm{P} 25 \\
\mathrm{TiO}_{2} \text { by a factor of } 1.5\end{array}$ \\
\hline Štengl et al. [70] & Thermal treated TNTs & 4-Chlorophenol & The degradation potential is inferior to that of $\mathrm{P} 25 \mathrm{TiO}_{2}$ \\
\hline Nakahira et al. [36] & Pure TNTs & $\mathrm{HCHO}$ & $\begin{array}{l}\text { Reaction rate of TNTs is larger than that of } \mathrm{P} 25 \mathrm{TiO}_{2} \text { by a } \\
\text { factor of } 1.6\end{array}$ \\
\hline \multicolumn{4}{|l|}{ Ion exchangeable and adsorption } \\
\hline Sun and $\mathrm{Li}[31]$ & None & $\mathrm{Co}^{2+}, \mathrm{Cu}^{2+}, \mathrm{Ni}^{2+}, \mathrm{NH}_{4}^{+}$ & $\begin{array}{l}\text { To verify the feasibility of TNTs as a ion-exchangeable } \\
\text { materials }\end{array}$ \\
\hline Umek et al. [78] & None & $\mathrm{NO}_{2}$ adsorption & $\mathrm{NO}_{2}$ can be reduced as $\mathrm{NO}$ in the presence of $\mathrm{Na}^{+}$ \\
\hline \multicolumn{4}{|l|}{ Photochemistry and electrochemistry } \\
\hline Li et al. [84] & None & Lithium ion battery & $\begin{array}{l}\text { Initial discharge capacity is larged than that of } \mathrm{TiO}_{2} \\
\text { electrode by a factor of } 30-50\end{array}$ \\
\hline \multicolumn{4}{|l|}{ Other pioneering application } \\
\hline Lin et al. [46] & Sulfated-TNTs & Esterification reaction & Reaction rate was increased by a factor of 5 \\
\hline Miao et al. [86] & $\mathrm{Ag} / \mathrm{AgCl}-\mathrm{TNTs}$ & Photochromism & Ag/TNTs exhibited multicolor photochromism \\
\hline Kasuga [82] & $\mathrm{Ca}-\mathrm{TNTs}$ & Biocompatibility & New bone generate after 7 day implantation in rat \\
\hline Kim et al. [59] & $\begin{array}{l}\text { Electrodeposition } \\
\text { process/thermal treated TNTs }\end{array}$ & Dry-sensitized solar celles & $\begin{array}{l}\text { Photocurrent density of TNTs film annealed at } 500{ }^{\circ} \mathrm{C} \text { was } \\
15.67 \mathrm{~mA} \mathrm{~cm}^{-2} \text {, which was larger than that of TNTs films } \\
\text { fabricated doctor-blade method by a factor of } 10\end{array}$ \\
\hline Hu et al. [81] & $\begin{array}{l}\text { Pd supported on carbonized } \\
\text { TNTs }\end{array}$ & Conductivity & $\begin{array}{l}\text { Conductivity is increased than that of } \mathrm{Pd} / \mathrm{C} \text { by a factor of } \\
1.5-3\end{array}$ \\
\hline He et al. [83] & Ag-supported/TiO $2 / \mathrm{TNTs}$ & Conductivity & $\begin{array}{l}\text { Ag/TNTs improve the reversibility capacity and the cycling } \\
\text { stability of pure TNTs }\end{array}$ \\
\hline Dominko et al. [54] & TNTs-derivate: $\mathrm{Na}_{2} \mathrm{Ti}_{6} \mathrm{O}_{13}$ & Lithium ion battery & $\begin{array}{l}\text { To verify the feasibility of } \mathrm{Na}_{2} \mathrm{Ti}_{6} \mathrm{O}_{13} \text { as a new negative } \\
\text { electrode }\end{array}$ \\
\hline Yu and Zhang [80] & Vanadium oxide/titanate & Capacitance & $\begin{array}{l}\text { The electrochemical capacitor of composite is larger than } \\
\text { that of } \mathrm{V}_{2} \mathrm{O}_{5}\end{array}$ \\
\hline Kasuga [82] & Acid-treated TNTs & Conductivity & Conductivity is increased by a factor of $50-100$ \\
\hline Tokudome and Miyauchi [79] & N-doped TNTs & Band gap determination & $\begin{array}{l}\text { The refractive indices are lower than that of a } \\
\text { polycrystalline anatase } \mathrm{TiO}_{2} \text { thin film }\end{array}$ \\
\hline
\end{tabular}

\subsection{Photocatalysis}

Regarding the photo-degradation of propylene, the effect of annealing temperature on the photocatalysis ability of TNTs was revealed by Zhang et al. [17]. TNTs treated at $300{ }^{\circ} \mathrm{C}$ possessed the best photocatalytic ability among the thermally treated TNTs; however, all of them presented inferior performances to that of Degussa P25 $\mathrm{TiO}_{2}$. The same result was 
also demonstrated by Štengl et al. [70] where they derived titanium nanorod from the post-thermal treatment of TNTs and investigated the corresponding photocatalytic ability for 4chlorophenol degradation. They indicated that even though the photocatalytic potential of titanium nanorods was inferior to that of commercial Degussa $\mathrm{P} 25 \mathrm{TiO}_{2}$, the titanium nanorods still exhibited good ability toward the 4-chlorophenol degradation owing to its high crystallization. Yu et al. [56] have also examined the photocatalytic oxidation of acetone over TNTs under thermal treatment $\left(300-700^{\circ} \mathrm{C}\right)$, which presented better photoability than commercial $\mathrm{P} 25 \mathrm{TiO}_{2}$ owing to the better pore volume and surface area. When the calcination temperature exceeds $700^{\circ} \mathrm{C}$, the photocatalytic ability disappear because of the absence of anatase and the decrease in pore volume and surface area. A similar study has also been presented by Xu et al. [71] where the degradation of methyl organic material was used as an indicator for the photocatalytic potential of $\mathrm{Zn}$ surfacedoped TNTs. They assigned the low photoactivity of Zn/TNTs calcined at $300{ }^{\circ} \mathrm{C}$ for the uncompleted complex decomposition on nanotube surface. The enhanced photoactivity in this case was ascribed to the $\mathrm{Zn}$ ions facilitating the charge separation, and also the larger surface area and pore size of TNTs. In a separate study, the calcined TNTs at $400{ }^{\circ} \mathrm{C}$ has been evidenced to be more abundant in $\mathrm{OH}$ concentration than $\mathrm{TiO}_{2} / \mathrm{SiO}_{2}$ [72], which also support the feasibility of TNTs being applied on the photocatalysis. Furthermore, they indicated that both extended capacity of UV-light absorption and large specific surface of TNTs were predominant factors for the excellent photocatalytic performance in pentachlorophenol degradation.

Anatase $\mathrm{TiO}_{2}$ nanofibers can also be obtained from the hydrothermally post-treatment of TNTs [56]. This report revealed the photocatalytic potential of anatase $\mathrm{TiO}_{2}$ nanofiber for acetone degradation together with $\mathrm{CO}_{2}$ formation. The photocatalytic performance was also indicated to exceed that of the commercial P25 $\mathrm{TiO}_{2}$ owing to the demonstrated larger surface area, smaller crystallite size, and higher pore volume. The photocatalytic ability of TNTs and $\mathrm{H}_{2} \mathrm{O}_{2}$-modified TNTs with ultrahigh crystalline content for trimethylamine degradation have also been examined [45], where the oxidant efficiency of modified TNTs exceeded that of TNTs by a factor of 2 . This phenomenon can be attributed to the compensation of the oxygen vacancy because of $\mathrm{H}_{2} \mathrm{O}_{2}$ modification.

\subsection{Support/carriers}

Hodos et al. [63] communicated the first successful photoactivation of TNTs by CdS particles. Hsu et al. [73] and Kukovecz et al. [64] have reported the related synthesis methods of CdS/TNTs, but did not apply such nanocomposites on some fields. Idakiev et al. [74] also studied the fabrication of Ausupported TNTs and the feasibility on water-gas shift reaction (WGS reaction). The performance of WGS reaction over Ausupported TNTs was enhanced by as much as four times that of $\mathrm{Au} / \mathrm{Al}_{2} \mathrm{O}_{3}$. Excluding the contribution from Au particles, the enhanced activity for Au-supported TNTs may be attributed to the perimeter interaction between Au particles and TNTs, the weak acidity contributed by TNTs, and the specific structure of TNTs. However, they also found that part of Au particles inserted into the tube hollows would shelter the active sites. In another study, conducted by Chien et al. [75], Pt/Au nanosize particles supported on TNTs was used to investigate $\mathrm{CO}_{2}$ hydrogenation and $\mathrm{CO}$ oxidation. TNTs subjected to $\mathrm{Cu}$ impregnation was also applied to examine the catalytic ability on NO conversion [20]. Comparing the catalytic ability of $\mathrm{Cu} / \mathrm{TNTs}$ to that of $\mathrm{Cu} / \mathrm{TiO}_{2}$, this report ascribed the excellent catalytic performance of $\mathrm{Cu} / \mathrm{TNTs}$ to the thorough dispersion of $\mathrm{Cu}$ on the surface of TNTs and the high surface area of TNTs. TNTs was also used as the support of Pd particles to investigate the double-bonded migration reaction [76]. Pt-entrapped TNTs based on decomposition of HCHO was also investigated by Nakahira et al. [77]. In a separate report where TNTs were used as the carrier of benzoic acid (BA) [35], BA molecules could be dispersed in monolayer on the surface of TNTs and carboxylate species could form owing to the reaction between the carboxylic acid functionality and hydroxyl groups of TNTs. Also, the utmost monolayer dispersion capacity was demonstrated as being $0.55 \mathrm{~g} \mathrm{BA} \mathrm{g}^{-1}$ TNTs.

\subsection{Ion-exchangeable and adsorption}

Sun and Li [31] first investigated the ion-exchangeable ability of TNTs where the characterizations of metal-substituted TNTs were influenced by the intercalation of transition metals. The intercalation of transition-metal-ions into the lattice of TNTs was ascribed to the electrostatic interactions between the negatively charged host lattice and positively charged cationic ions. Meanwhile, they also indicated that UV/vis spectrums of $\mathrm{Co}^{2+}$, $\mathrm{Cu}^{2+}$, and $\mathrm{Ni}^{2+}$-substituted TNTs demonstrated broad and strong absorption in the visible-metal range owing to the $\mathrm{d}-\mathrm{d}$ transition of these transition-metal ions. This feature is believed to possess a positive impact on some photo-related fields. Regarding the application of TNTs on adsorption, the impact of structure and morphology on $\mathrm{NO}_{2}$ adsorption over nanotubes and nanoribbons has been reported by Umek et al. [78]. In their electron paramagnetic resonance (EPR) determinations, physissorbed $\mathrm{NO}_{2}$ molecules with a trace amount of $\mathrm{NO}$ were observed in the case of nanotubes, while NO dominated in the case of nanoribbons. They indicated that $\mathrm{Na}$ atoms along with the hydrolyzed surface of nanoribbons can catalyze $\mathrm{NO}_{2}$, leading to the formation of $\mathrm{NO}_{3}$ and $\mathrm{NO}$. On the other hand, nanotubes with a lower amount of $\mathrm{Na}$ atoms preferentially provide sites for $\mathrm{NO}_{2}$ adsorption and few opportunities for $\mathrm{NO}_{2}$ catalysis.

\subsection{Photochemistry and electrochemistry}

Modified N-doped TNTs was demonstrated by Tokudome and Miyauchi [79], in which the band-gap of N-doped TNTs was reported as $3.17 \mathrm{eV}$ while that of pure anatase and TNTs were 3.22 and $3.42 \mathrm{eV}$, respectively. The enhanced attributes, both low-reflective and transparent, were reported to be due to the inner cavities of the nanotubes and void spaces between nanotubes. Further support was also provided by the degradation of gaseous isopropanol over N-doped TNTs being feasible under 
the illumination of $410-500 \mathrm{~nm}$. In a separate study, vanadium oxide/titanate composite nanorods have also been fabricated to investigate the corresponding electrochemical capacitance [80]. This report indicated that the composite materials were orderly grown together in the form of bundles $10-20 \mu \mathrm{m}$ in length and $100-300 \mathrm{~nm}$ in diameter. Illustrated cyclic voltammetric curves indicated that the electrochemical capacitance and voltammetric current of the composites nanorods were better than that of pure $\mathrm{V}_{2} \mathrm{O}_{5}$. Conductivity of TNTs was also enhanced by carbonization treatment [81], where the enhanced performance of $\mathrm{Pd} / \mathrm{TiO}_{2} \mathrm{C}$ in conductivity was ascribed to the carbonization and efficient mass transport on the surface of TNTs. Kasuga et al. [82] has also highlighted acid treatment of TNTs on the electric conductivities, where proton-TNTs, phosphoric treated TNTs, sulfuric treated TNTs, and perchloric treated TNTs were $1.6 \times 10^{-4}, 1.4 \times 10^{-2}, 8 \times 10^{-3}$, and $1.6 \times 10^{-2} \mathrm{~S} \mathrm{~cm}^{-1}$, respectively. This result indicated that the involvement of surface modification dominated the conductivity features, which was believed to be related to the dissociation degree of applied acid. Ag-modified TNTs were also reported by $\mathrm{He}$ et al. [83], in which the surface electronic conductivity of Ag/TNTs can be improved more completely than bare TNTs. As such, Ag-modified TNTs significantly decreased cell polarization along with the enhancement of reversible capacity and cycling stability of the bare TNTs.

Zhang's group $[84,85]$ first investigated the electrochemical properties of anatase $\mathrm{TiO}_{2}$ nanotube, and found its promising behavior in lithium intercalation batteries. In their study, a high discharge rate capability and excellent cycling stability of TNTs were observed. Based on the examination of columbic efficiency, lithium intercalation and its efficient release from TNTs could also be found in the layered wall structure of TNTs. This proposal was supported in that the larger interlayer distance within TNTs provide a promising channel for lithium ion intercalation and release reversibly [47]. $\mathrm{Na}_{2} \mathrm{Ti}_{6} \mathrm{O}_{13}$, a TNT-derived material, within tunnel structure has also been evidenced to provide accommodations for lithium insertion. Based on galvanostatic measurements, such insertion can raise the efficiency of lithium ion batteries if applied on lithium-intercalated $\mathrm{Na}_{2} \mathrm{Ti}_{6} \mathrm{O}_{13}$ as the negative electrode in the field of lithium [54].

Another promising application in the solar energy related field was reported by Kim et al. [59]. In this study, TNT film was fabricated on $\mathrm{F}-\mathrm{SnO}_{2}$ coated glass (FTO) via electrophotic deposition. The photocurrent densities of the dye-sensitized solar cells gradually increased with the annealing temperature of interest $\left(450-500{ }^{\circ} \mathrm{C}\right)$. The decrease in photocurrent densities for temperatures over $500{ }^{\circ} \mathrm{C}$ was attributed to the thermal limitation of FTO substrate and the decline of surface area of TNTs. Another conclusion demonstrated in this paper is that the sodium containing TNTs and poor interfacial adhesion between TNTs and FTO substrate can also cause low photocatalytic photocurrent density.

\subsection{Other pioneering applications}

The application of sulfated TNTs on the esterification reaction was exhibited by Lin et al. [46]. Based on the observation of ester yield, the esterification reaction rate of sulfated TNTs was reported to be larger than that of anatase $\mathrm{TiO}_{2}$ powder by a factor of five. Another study querying the application of Ca-TNTs was also developed where it was used for bone repair in filling defective areas of bones [82]. Newly formed bone was found around Ca-TNTs after being implanted in the femur of a rat for 7 days. This phenomenon indicated that $\mathrm{Ca}-\mathrm{TNT}$ s induced excellent bone tissue regeneration at implantation. In a separate study, the modified Ag/AgCl-TNTs were used as photochromism materials, which gained prominence in smart window, displays, and optical memories [86]. In this report it was concluded that multicolor photochromism corresponding to that of incident light was present in the case of Ag modified TNTs. This behavior, which subsequently led to either permanence of presented colored samples for several days under fluorescent light or bleach by UV irradiation, was attributed to the improvement of homogeneous size distribution and photochromic features.

\section{Concluding remarks}

In this review, an extensive spectrum of hydrothermal TNTs have been demonstrated where five categorizations have been classified, including (a) characterization and formation mechanism, (b) fabrication factors, (c) post-treatment, (d) modifications and (e) applications. In spite of many studies having attempted to investigate the chemical structure and formation mechanism of TNTs, it is still ambiguous and leaves much space to explore and explain. Post-treatment, believed to improve the activity of TNTs, may, on the downside, adversely affect its physical characterizations. It is, therefore, the opinion of the authors that novel and promising post-treatment or modifying techniques should be developed further, as these techniques can enhance the activities of TNTs while at the same time ensuring that the techniques do not compromise its physical characterizations. Furthermore, the modification of hydrothermal treatment also opens new perspectives in the investigation of enhanced formation kinetics and the chemical/physical attributes of TNTs. From literature surveys, so far, few studies have been dedicated to this aspect and it should be another potential aspect in TNT investigations. TNTs with high surface area, ion exchangeable ability, and photocatalytic potential present an attractive avenue and is an ideal candidate in extensive applications. In fact, the versatility and feasibility of TNTs on practical applications have been demonstrated, and are still in the ascendant.

\section{References}

[1] P. Hoyer, Formation of titanium dioxide nanotube array, Langmuir 12 (1996) 1411-1413.

[2] J.H. Jung, H. Kobayashi, K.J.C. van Bommel, S. Shinkai, T. Shimizu, Chem. Mater. 14 (2002) 1445-1447.

[3] J.H. Lee, I.C. Leu, M.C. Hsu, Y.W. Chung, M.H. Hon, Fabrication of aligned $\mathrm{TiO}_{2}$ one-dimensional nanostructured arrays using a one-step templating solution approach, J. Phys. Chem. B 109 (2005) 13056-13059.

[4] T. Kasuga, M. Hiramatsu, A. Hoson, T. Sekino, K. Niihara, Formation of titanium oxide nanotube, Langmuir 14 (1998) 3160-3163.

[5] V. Zwilling, M. Aucouturier, E. Darque-Ceretti, Structure and physicochemistry of anodic oxide films on titanium and TA6V alloy, Surf. Interface Anal. 27 (1999) 629-637. 
[6] D. Gong, C.A. Grimes, O.K. Varghese, W. Hu, R.S. Singh, Z. Chen, E.C. Dickey, Titanium oxide nanotube arrays prepared by anodic oxidation, J. Mater. Res. 16 (2001) 3331-3334.

[7] O.K. Varghese, D. Gong, M. Paulose, C.A. Grimes, E.C. Dickey, Crystallization and high-temperature structural stability of titanium oxide nanotube arrays, J. Mater. Res. 18 (2003) 156-165.

[8] O.K. Varghese, M. Paulose, K. Shankar, G.K. Mor, C.A. Gong, Grimes, Water-photolysis properties of micro-length highly-ordered titanate nanotubes-arrays, J. Nanosci. Nanotechnol. 5 (2005) 1158-1165.

[9] A. Ghicov, H. Tsuchiya, J.M. Macak, P. Schmuki, Titanium oxide nanotubes prepared in phosphate electrolytes, Electrochem. Commun. 7 (2005) $505-509$.

[10] H. Tsuchiya, J.M. Macak, L. Taveira, E. Balaur, A. Ghicov, K. Sirotna, P. Schmuki, Self-organized $\mathrm{TiO}_{2}$ nanotubes prepared in ammonim fluoride containing acetic acid electrolytes, Electrochem. Commun. 7 (2005) 576-580.

[11] T. Kasuga, M. Hiramatsu, A. Hoson, T. Sekino, K. Niihara, Titania nanotubes prepared by chemical processing, Adv. Mater. 11 (1999) 1307-1311.

[12] G.H. Du, Q. Chen, R.C. Che, Z.Y. Yuan, L.M. Peng, Preparation and structure analysis of titanium oxide nanotubes, Appl. Phys. Lett. 79 (2001) 3702-3704

[13] Q. Chen, W.Z. Zhou, G.H. Du, L.M. Peng, Tritanate nanotubes made via a single alkali treatment, Adv. Mater. 14 (2002) 1208-1211.

[14] Q. Chen, G.H. Du, S. Zhang, L.M. Peng, The structure of tritinate nanotubes, Acta Cryst. B 58 (2002) 587-593.

[15] S. Zhang, L.M. Peng, Q. Chen, G.H. Du, G. Dawson, W.Z. Zhou, Formation mechanism of $\mathrm{H}_{2} \mathrm{Ti}_{3} \mathrm{O}_{7}$ nanotubes, Phys. Rev. Lett. 91 (2003), 256103-1:4.

[16] J. Yang, Z. Jin, X. Wang, W. Li, J. Zhang, S. Zhang, X. Guo, Z. Zhang, Study on composition, structure and formation process of nanotube $\mathrm{Na}_{2} \mathrm{Ti}_{2} \mathrm{O}_{4}(\mathrm{OH})_{2}$, Dalton Trans. (2003) 3898-3901.

[17] M. Zhang, Z. Jin, J. Zhang, X. Guo, J. Yang, W. Li, X. Wang, Z. Zhang, Effect of annealing temperature on morphology, structure, and photocatalytic behavior of nanotubed $\mathrm{H}_{2} \mathrm{Ti}_{2} \mathrm{O}_{4}(\mathrm{OH})_{2}$, J. Mol. Catal. A 217 (2004) 203-210.

[18] S. Zhang, W. Li, Z. Jin, J. Yang, J. Zhang, Z. Du, Z. Zhang, Study on ESR and inter-related properties of vacumm-dehydrated nanotube titanic acid, J. Solid State Chem. 11 (2004) 1365-1371.

[19] A. Thorne, A. Kruth, D. Tunstall, J.T.S. Irvine, W. Zhou, Formation, structure, and stability of titanate nanotubes and their proton conductivity, J. Phys. Chem. B 109 (2005) 5439-5444.

[20] C.C. Tsai, H. Teng, Regulation of the physical characteristics of titania nanotube aggregates synthesized from hydrothermal treatment, Chem. Mater. 16 (2004) 4352-4358.

[21] C.C. Tsai, $\mathrm{H}$. Teng, Structure features of nanotubes synthesized from $\mathrm{NaOH}$ treatment on $\mathrm{TiO}_{2}$ with different post-treatment, Chem. Mater. 18 (2006) $367-373$.

[22] J.N. Nian, H. Teng, Hydrothermal synthesis of single-crystalline anatase $\mathrm{TiO}_{2}$ nanorods with nanotubes as the precursor, J. Phys. Chem. B 110 (2006) 4193-4198.

[23] C.C. Tsai, J.N. Nian, H. Teng, Mesoporous nanotube aggregates obtained from hydrothermally treating $\mathrm{TiO}_{2}$ with $\mathrm{NaOH}$, Appl. Surf. Sci. 253 (2006) 1898-1902.

[24] G.K. Mor, O.K. Varghese, M. Paulose, K. Shankar, C.A. Grimes, A review on highly ordered, vertically oriented $\mathrm{TiO}_{2}$ nanotube arrays: fabrication, material properties, and solar energy applications, Sol. Energy Mater. Sol. Cells 90 (2006) 2011-2075.

[25] B. Poudel, W.Z. Wang, C. Dames, J.Y. Huang, S. Kunwar, D.Z. Wang, D. Banerjee, G. Chen, Z.F. Ren, Formaiton of crystallized titania nanotubes and their transformation into nanowires, Nanotechnology 16 (2005) 1935-1940.

[26] Y.Q. Wang, G.Q. Hu, X.F. Duan, H.L. Sun, Q.K. Xue, Microstructure and formation mechanism of titanim dioxide nanotubes, Chem. Phys. Lett. 365 (2002) 427-431.

[27] X. Wu, Q.Z. Jiang, Z.F. Ma, M. Fu, W.F. Shangguan, Synthesis of titania nanotubes by microwave irradiation, Solid State Commun. 136 (2005) 513-517.

[28] X. Wu, Q.Z. Jiang, Z.F. Ma, W.F. Shangguan, Synthesis of titania nanotubes by microwave method, Chin. J. Inorg. Chem. 22 (2006) 341-345.
[29] R. Ma, Y. Banda, T. Sasaki, Nanotubes of lepidocrocite titanates, Chem. Phys. Lett. 380 (2003) 577-582.

[30] R. Ma, K. Fukuda, T. Sasaki, M. Osada, Y. Bando, Structure features of titanate nanotubes/nanobelts revealed by Raman, X-ray absorption fine structure and electron diffraction characterizations, J. Phys. Chem. B 109 (2005) 6210-6214.

[31] X. Sun, Y. Li, Synthesis and characterization of ion-exchangeable titanate nanotubes, Chem. Eur. J. 9 (2003) 2229-2238.

[32] D.V. Bavykin, J.M. Friedrich, A.A. Lapkin, F.C. Walsh, Stability of aqueous suspensions of titanate nanotubes, Chem. Mater. 18 (2006) 1124 1129.

[33] N. Wang, H. Lin, J. Li, X. Yang, B. Chi, C. Lin, Effect of annealing temperature on phase transition and optical property of titanate nanotubes prepared by ion exchange approach, J. Alloys Compd. 472 (2006) 311-314.

[34] Z.Q. Song, H.Y. Xu, K.W. Li, H.W. Wang, H. Yan, Hydrothermal synthesis and photocatalytic properties of titanium acid $\mathrm{H}_{2} \mathrm{Ti}_{2} \mathrm{O}_{5}\left(\mathrm{H}_{2} \mathrm{O}\right)$ nanosheets, J. Mol. Catal. A: Chem. 239 (2005) 87-91.

[35] W. Wang, J. Zhang, H. Huang, Z. Wu, Z. Zhang, Investigation of monolayer dispersion of benzoic acid supported on the structure of $\mathrm{H}$-titanate nanotubes, Appl. Surf. Sci. 253 (2007) 5393-5399.

[36] A. Nakahira, W. Kato, M. Tamai, T. Isshiki, K. Nishio, Synthesis of nanotube from a layered $\mathrm{H}_{2} \mathrm{Ti}_{4} \mathrm{O}_{9}\left(\mathrm{H}_{2} \mathrm{O}\right)$ in a hydrothermal treatment using various titania sources, J. Mater. Sci. 39 (2004) 4239-4245.

[37] B.D. Yao, Y.F. Chan, X.Y. Zhang, W.F. Zhang, Z.Y. Yang, N. Wang, Formation mechanism of $\mathrm{TiO}_{2}$ nanotubes, Appl. Phys. Lett. 82 (2003) 281-283.

[38] L. Zhang, H. Lin, N. Wang, C. Lin, J. Li, The evolution of morphology and crystal form of titanate nanotubes under calcination and its mechanism, $\mathrm{J}$. Alloys Compd. 431 (2007) 230-235.

[39] Á. Kukovecz, M. Hodos, E. Horváth, G. Radnóczi, Z. Kónya, I. Kiricsi, Oriented crystal growth model explains the formation of titania nanotubes, J. Phys. Chem. B 109 (2005) 17781-17783.

[40] R. Ma, Y. Bando, T. Sasaki, Directly rolling nanosheets into nanotubes, J. Phys. Chem. B 108 (2004) 2115-2119.

[41] M. Wei, Y. Konishi, H. Zhou, H. Sugihara, H. Arakawa, Formation of nanotubes $\mathrm{TiO}_{2}$ from layered titanate particles by a soft chemical process, Solid State Commun. 133 (2005) 493-497.

[42] D.S. Seo, J.K. Kim, H. Kim, Preparation of nanotube-shaped $\mathrm{TiO}_{2}$ powder, J. Cryst. Growth 229 (2001) 428-432.

[43] Z.Y. Yuan, B.L. Su, Titanium oxide nanotubes, nanofibers and nanowires, Colloids Surf. A 241 (2004) 173-183.

[44] Z.Y. Yuan, J.F. Colomer, B.L. Su, Titanium oxide nanoribbons, Chem. Phys. Lett. 363 (2002) 362-366.

[45] M.A. Khan, H.T. Jung, O.B. Yang, Synthesis and characterization of ultrahigh crystalline $\mathrm{TiO}_{2}$ nanotubes, J. Phys. Chem. B 110 (2006) 6626-6630.

[46] C.H. Lin, S.H. Chien, J.H. Chao, C.Y. Sheu, Y.C. Cheng, Y.J. Huang, C.H. Tsai, The synthesis of sulfated titanium oxide nanotubes, Cataly. Lett. 80 (2002) 153-159.

[47] Y. Lan, X. Gao, H. Zhu, Z. Zheng, T. Yan, F. Wu, S.P. Ringer, D. Song, Titanate nanotubes and nanorods prepared from rutile powder, Adv. Funct. Mater. 15 (2005) 1310-1318.

[48] L.Q. Weng, S.H. Song, S. Hodgson, A. Baker, J. Yu, Synthesis and characterization of nanotubular titanates and titania, J. Eur. Ceram. Soc. 26 (2006) $1405-1409$.

[49] E. Morgado Jr., M.A.S. de Abreu, O.R.C. Pravia, B.A. Marinkovic, P.M Jardim, F.C. Rizzo, A.S. Araújo, A study on the structure and thermal stability of titanate nanotubes as a function of sodium content, Solid State Sci. 8 (2006) 888-900.

[50] R. Yoshida, Y. Suzuki, S. Yoshikawa, Effects of synthetic conditions and heat-treatment on the structure of partially ion-exchanged titanate nanotubes, Mater. Chem. Phys. 91 (2005) 409-416.

[51] Y. Suzuli, S. Yoshikawa, Synthesis and thermal analyses of $\mathrm{TiO}_{2}$-derived nanotubes by the hydrothermal method, J. Mater. Res. 19 (2004) 982-985.

[52] A.R. Armstrong, G. Armstrong, J. Canales, P.G. Bruce, $\mathrm{TiO}_{2}-\mathrm{B}$ nanowires, Angew. Chem. Int. Ed. 43 (2004) 2286-2288.

[53] J. Yu, H. Yu, B. Cheng, C. Trapails, Effects of calcination temperature on the microstructures and photocatalytic acitivity of titanate nanotubes, $\mathrm{J}$. Mol. Catal. A: Chem. 249 (2006) 135-142. 
[54] R. Dominko, E. Baudrin, P. Umek, D. Arcon, M. Gaberšcek, J. Jamnik, Reversible lithium insertion into $\mathrm{Na}_{2} \mathrm{Ti}_{6} \mathrm{O}_{13}$ structure, Electrochem. Commun. 8 (2006) 673-677.

[55] H.Y. Zhu, Y. Lan, X.P. Gao, S.P. Ringer, R.F. Zheng, D.Y. Song, J.C. Zhao, Phase transition between nanostructures of titanate and titanium dioxides via simple wet-chemical reactions, J. Am. Chem. Soc. 127 (2005) 6730-6736.

[56] J. Yu, H. Yu, B. Cheng, X. Zhao, Q. Zhang, Preparation and photocatalytic activity of mesoporous anatase $\mathrm{TiO}_{2}$ nanofibers by a hydrothermal method, J. Photochem. Photobiol. A: Chem. 182 (2006) 121-127.

[57] R. Ma, T. Sasaki, Y. Bando, Layer-by-layer assembled multilayer films of titanate nanotubes, Ag- or Au-loaded nanotubes, and nanotubes/nanosheets with polycations, J. Am. Chem. Soc. 126 (2004) 10382-10388.

[58] G.S. Kim, V.P. Godbole, H.K. Seo, Y.S. Kim, H.S. Shain, Sodium removal from titanate nanotubes in electrodeposition process, Electrochem. Commun. 8 (2006) 471-474.

[59] G.S. Kim, H.K. Seo, V.P. Godbole, Y.S. Kim, O.B. Yang, H.S. Shin, Electrodeposition of titanate nanotubes from commercial titania nanoparticles: application to dye-senstitized solar cells, Electrochem. Commun. 8 (2006) 961-966.

[60] V.P. Godbole, Y.S. Kim, G.S. Kim, M.A. Dar, H.S. Shin, Synthesis of titanate nanotubes and its processing by different methods, Electrochim. Acta 52 (2006) 1781-1787.

[61] C. Zhang, X. Jiang, B. Tian, X. Wang, X. Zhang, Z. Du, Modification and assembly of titanate sodium nanotubes, Colloids Surf. A 257/258 (2005) 521-524.

[62] Y.Zhao, J. Jin, X. Yang, Hydrothermal synthesis of titanate nanowire arrays, Mater. Lett. 61 (2007) 384-388.

[63] M. Hodos, E. Horváth, H. Haspel, Á. Kukovecz, Z. Kónya, I. Kiricsi, Photosenstization of ion-exchangeable titanate nanotubes by $\mathrm{CdS}$ nanoparticles, Chem. Phys. Lett. 399 (2004) 512-515.

[64] Á. Kukovecz, M. Hodos, Z. Kónya, I. Kiricsi, Complex-assisted onestep synthesis of ion-exchangeable titanate nanotubes decorated with $\mathrm{CdS}$ nanoparticles, Chem. Phys. Lett. 411 (2005) 445-449.

[65] L. Ren, X. Huang, F. Sun, X. Je, Preparation and characterization of doped $\mathrm{TiO}_{2}$ nanodandelion, Mater. Lett. 61 (2007) 427-431.

[66] Y.C. Zhu, H.L. Li, Y. Koltypin, Y.R. Hacohenb, A. Gedanken, Sonochemical synthesis of titania whiskers and nanotubes, Chem. Commun. 24 (2001) 2616-2617.

[67] Y. Ma, Y. Lin, X. Xiao, X. Zhou, X. Li, Sonication-hydrothermal combination technique for the synthsis of titante nanotubes from commercially available precursors, Mater. Res. Bull. 41 (2006) 237-343.

[68] Y.A. Wang, J. Yang, J. Zhang, H. Liu, Z. Zhang, Microwave-assisted preparation of titanate nanotubes, Chem. Lett. 34 (2005) 1168-1169.

[69] J. Zhang, Y.A. Wang, J. Yang, J. Chen, Z. Zhang, Microwave-assisted synthesis of potassium titanate nanowires, Mater. Lett. 60 (2006) 3015-3017

[70] V. Štengl, S. Bakardjieva, J. Šubrt, E. Veçerníková, L. Szatmary, M. Klementová, V. Balek, Sodium titanate nanorods: preparation, microstructure characterization and photocatalytic activity, Appl. Catal. B: Environ. 63 (2006) 20-30.

[71] J.C. Xu, M. Lu, X.Y. Guo, H.L. Ki, Zinc ions surface-doped titanium dioxide nanotubes and its photocatalysis activity for degradation of methyl orange in water, J. Mol. Catal. A: Chem. 226 (2005) 123-127.

[72] Z. Gao, S. Yang, C. Sun, J. Hong, Microwave assisted photocatalytic degradation of pentachlorophenol in aqueous $\mathrm{TiO}_{2}$ nanotube suspension, Sep. Purif. Technol. 58 (2007) 24-31.

[73] M.C. Hsu, I.C. Leu, Y.M. Sun, M.H. Hon, Fabrication of CdS/TiO 2 coaxial composite nanocables arrays by liquid-phase deposition, J. Cryst. Growth 285 (2005) 642-648.

[74] V. Idakiev, Z.Y. Yuan, T. Tabakova, B.L. Su, Titanium oxide nanotubes as supports of nano-sized gold catalysts for low temperature water-gas shift reaction, Appl. Catal. A: Chem. 281 (2005) 149-155.

[75] S.H. Chien, Y.C. Liou, M.C. Kuo, Preparation and characterization of nanosized $\mathrm{Pt} / \mathrm{Au}$ particles on $\mathrm{TiO}_{2}$ nanotubes, Synth. Met. 152 (2005) 333-336.

[76] L. Torrente-Murciano, A.A. Lapkin, D.V. Bavykin, F.C. Walsh, K. Wilson, Highly selective $\mathrm{Pd} /$ titanate nanotube catalysts for the double-bond migration reaction, J Catal. 245 (2007) 272-278.

[77] A. Nakahira, T. Kubo, Y. Yamasaki, T. Suzuki, Y. Ikuhara, Synthesis of Pt-entrapped titanate nanotubes, Jpn. J. Appl. Phys., Part 144 (2005) L690-L692.

[78] P. Umek, P. Cevc, A. Jesih, A. Gloter, C.P. Ewels, D. Arcon, Impact of structure and morphology on gas adsorption of titanate-based nanotubes and nanoribbons, Chem. Mater. 17 (2005) 5945-5950.

[79] H. Tokudome, M. Miyauchi, N-doped nanotube with visible light activity, Chem. Lett. 9 (2004) 1108-1109.

[80] L. Yu, X. Zhang, Hydrothermal synthesis and characterization of vanadium oxide/titanate composite nanorods, Mater. Chem. Phys. 87 (2004) 168-172.

[81] F. Hu, F. Ding, S. Song, P.K. Shen, Pd electrocatalyst supported on carbonized $\mathrm{TiO}_{2}$ nanotube for ethanol oxidation, J. Power Sources 163 (2006) 319-415.

[82] T. Kasuga, Formation of titanium oxide nanotubes using chemical treatments and their characteristic properties, Thin Solid Films 496 (2006) 141-145.

[83] B.L. He, B. Dong, H.L. Li, Preparation and electrochemical properties of Ag-modified $\mathrm{TiO}_{2}$ nanotube anode material for lithium-ion battery, Electrochem. Commun. 9 (2007) 425-430.

[84] J. Li, Z. Tang, Z. Zhang, H-titanate nanotube: a novel lithium intercalation host with large capacity and high rate capability, Electrochem. Commun. 7 (2005) 62-67.

[85] J. Li, Z. Tang, Z. Zhang, Pseudocapacitive characteristic of lithium ion storage in hydrogen titanate nanotubes, Chem. Phys. Lett. 418 (2006) 506-510.

[86] L. Miao, Y. Ina, S. Tanemura, T. Jiang, M. Tanemura, K. Kaneko, S. Toh, Y. Mori, Fabricaiton and photochromic study of titanate nanotubes loaded with silver nanoparticles, Surf. Sci. 13 (2007) 2792-2799. 